\title{
Determinants of dropout behaviour in a job training programme for disadvantaged youth
}

Citation for published version (APA):

de Crombrugghe, D. P. I., Espinoza, H., \& Heijke, J. A. M. (2010). Determinants of dropout behaviour in a job training programme for disadvantaged youth. Researchcentrum voor Onderwijs en Arbeidsmarkt, Faculteit der Economische Wetenschappen. ROA Research Memoranda No. 8 https://doi.org/10.26481/umaror.2010008

Document status and date:

Published: 01/01/2010

DOI:

10.26481/umaror.2010008

Document Version:

Publisher's PDF, also known as Version of record

\section{Please check the document version of this publication:}

- A submitted manuscript is the version of the article upon submission and before peer-review. There can be important differences between the submitted version and the official published version of record.

People interested in the research are advised to contact the author for the final version of the publication, or visit the DOI to the publisher's website.

- The final author version and the galley proof are versions of the publication after peer review.

- The final published version features the final layout of the paper including the volume, issue and page numbers.

Link to publication

\footnotetext{
General rights rights.

- You may freely distribute the URL identifying the publication in the public portal. please follow below link for the End User Agreement:

www.umlib.nl/taverne-license

Take down policy

If you believe that this document breaches copyright please contact us at:

repository@maastrichtuniversity.nl

providing details and we will investigate your claim.
}

Copyright and moral rights for the publications made accessible in the public portal are retained by the authors and/or other copyright owners and it is a condition of accessing publications that users recognise and abide by the legal requirements associated with these

- Users may download and print one copy of any publication from the public portal for the purpose of private study or research.

- You may not further distribute the material or use it for any profit-making activity or commercial gain

If the publication is distributed under the terms of Article $25 \mathrm{fa}$ of the Dutch Copyright Act, indicated by the "Taverne" license above, 


\section{Determinants of dropout behaviour in a job training programme for disadvantaged youths}

Denis de Crombrugghe

Henry Espinoza

Hans Heijke

\section{ROA Research Memorandum}

ROA-RM-2010/8

Research Centre for Education and the Labour Market Maastricht University

P.O. Box 616, 6200 MD Maastricht, The Netherlands

$\mathrm{T}+31433883647 \mathrm{~F}+31433884914$

secretary-roa-sbe@maastrichtuniversity.nl www.roa.n 


\title{
Determinants of dropout behaviour in a job training programme for disadvantaged youths
}

\author{
Denis de Crombrugghe \\ Henry Espinoza \\ Hans Heijke
}

ROA-RM-2010/8*

June 2010

Research Centre for Education and the Labour Market

Maastricht University

P.O. Box 616, 6200 MD Maastricht, The Netherlands

$\mathrm{T}+31433883647 \mathrm{~F}+31433884914$

secretary-roa-sbe@maastrichtuniversity.nl

www.roa.nl * The ROA Research Memorandum Series was created in order to make research results available for discussion,
before those results are submitted for publication in journals. 


\section{Abstract \\ Determinants of dropout behaviour in a job training programme for disadvantaged youths*}

A general conclusion of the youth job training programme (YJTP) evaluation literature is that these programmes are more effective when completed. Yet, YJTPs suffer from substantial dropout problems. This paper studies the extent of the dropout phenomenon and under which circumstances dropout is more likely among the participants of the YJTP Projoven-Peru. Projoven follows a two-step sequence design: a classroom training phase, which practically all candidates complete, and an internship, which is not offered to all. Controlling for potential selection into internship, we find that regional differences and internship conditions affect the dropout likelihood. We also distinguish between two different exit routes compared with training completion: i) dropping out of training for a job and ii) dropping out of training into unemployment or inactivity. Our estimates suggest that trainees who are male and have prior work experience are less likely to drop out into unemployment, but more likely to drop out for another job.

JEL classification: C34, I38, J24, M53.

Keywords: Youth job training programmes, Projoven, dropout.

Denis de Crombrugghe

Dept. of Quantitative Economics

Maastricht University

P.O. Box 616

6200 MD Maastricht

The Netherlands

d.decrombrugghe@maastrichtuniversity.nl
Hans Heijke

Dept. of Economics and ROA

Maastricht University

P.O. Box 616

6200 MD Maastricht

The Netherlands

h.heijke@maastrichtuniversity.nl

Henry Espinoza

Maastricht Graduate School of Governance

Maastricht University

P.O. Box 616

6200 MD Maastricht

The Netherlands

henry.espinozapena@maastrichtuniversity.nl

** We are grateful to participants of the EALE 2009 Conference (Tallinn), Eric Bonsang, and Bart Golsteyn for their valuable comments. Any remaining shortcomings are the responsibility of the authors. 


\section{Introduction}

Dropout is a widespread phenomenon in youth job training programmes (YJTPs). In Peru, only $60 \%$ of participants complete the training, and the completion rate ranges from $51 \%$ in Uruguay to $60 \%$ in the Dominican Republic, $74 \%$ in Chile, and $77 \%$ in Panama. Low completion rates challenge the capacity of YJTPs to effectively and efficiently accomplish their objectives. This is not only the case in Latin America. In the United States and Germany, only 58\% and 69\%, respectively, of YJTP participants complete the training. Heckman et al. (1998, 2000) demonstrate that, in the absence of an adjustment for dropout behaviour, the treatment effects of the Job Training Partnership Act tend to be underestimated. Furthermore, empirical evidence suggests that job training programmes are more effective once they are completed (Mealli et al., 1996; Chong and Galdo, 2006) and yield higher returns the longer the trainees are exposed to training (Flores-Lagunes et al., 2007; Kluve et al., 2007). Studies such as Chacaltana et al. (2003) and de Crombrugghe et al. (2010) conclude that the training may have no beneficial effects at all unless completed. These results raise concern about why trainees drop out and why they would start training if not determined to complete it.

Low completion rates can be seen as evidence of YJTPs not targeting the right individuals, YJTPs not considering particular regional/context features, and/or limitations of the programme characteristics. First, YJTPs target youngsters who possess particular features (poverty status, low educational attainment). Yet, other individual characteristics can enhance training returns. For the Latin American case, Betcherman et al. (2004) and Ibarrarán and Rosas (2008) find that YJTPs are more effective for women. De Crombrugghe et al. (2010) provide evidence that Projoven-Peru yields additional returns to individuals with no work experience. Individuals who, because of their characteristics, find that they do not benefit sufficiently from the training to compensate for their opportunity costs will not make the necessary effort to complete the programme. Second, economic circumstances or regional context can affect the dropout likelihood. These circumstances modify trainees' opportunity costs of undertaking training and the availability of internship opportunities. Third, course characteristics (students per course, workload, teacher experience, etc.) and the quality of the internship (presence of a written contract), usually unknown to the trainees

before the programme starts, can modify individual expectations about the returns of the training. Youngsters can drop out during the training if they realise that the programme is not going to yield the returns they hoped.

The aim of this paper is to find out why trainees drop out of YJTPs. We test whether individual characteristics, regional features, or training characteristics 
influence the likelihood to drop out. The goal is to examine the nature of the dropout phenomenon in the Peruvian YJTP Projoven. This programme makes for an interesting case study: Projoven is a YJTP similar in design to others in Latin America and it has dropout rates similar to other YJTPs in the region. Additionally, it provides a unique data set that allows matching trainee information with training provider characteristics and training course features.

Projoven is an ongoing YJTP started in 1996. The programme has trained more than 60,000 youngsters in 15 public calls. It facilitates the entry of economically disadvantaged youngsters (16-24 years old) to the formal labour market. The programme follows a two-step sequence design. First, the trainees attend three months of classroom training. Second, the trainees are placed in a three-month on-the-job training internship, if available, in principle. Projoven, which is run by the Peruvian Ministry of Labour, finances training institutions, so-called ECAPs, to provide the programme's participants with low-skill job training courses and, subsequently, place them in on-the-job training internships. Virtually all the trainees, around $96 \%$, on average, per public call, complete the first stage of the training. However, around $20 \%$ are not placed in internships by the ECAPs (involuntary dropouts) and, consequently, their compliance behaviour is not observed.

We use a probit model with sample selection to evaluate the determinants of the trainees' dropout decision. The probit model with sample selection takes into account the fact that the withdrawal decision is only observed for those trainees who are placed in internships. We also estimate a multinomial probit model to allow the effects of the explanatory variables to vary across two different exit routes (in comparison with training completion): i) dropping out of training for a job and ii) dropping out of training into unemployment or inactivity.

We find no evidence of selection into internship. It seems that ECAP characteristics influence the likelihood of placing trainees in internships. Our results suggest that trainees' dropout decisions follow a rational pattern. Trainees stay in the programme as long as they perceive evidence that it is worthwhile to do so. First, individuals with certain characteristics (males with work experience) that indicate higher training returns are less likely to drop out into unemployment, but more likely to drop out for another job. This is only distinguishable in the multinomial probit model. Second, in both models (probit with sample selection and multinomial probit), we find that in cities where fewer job opportunities are available (in comparison with Lima), trainees are also less likely to drop out. Finally, when the training conditions indicate chances of being hired on a permanent basis or the training firm is committed to the training activities (presence of a written contract), trainees are also less likely to drop out, regardless of the exit route. 
The remainder of this paper proceeds as follows. Section 2 presents a discussion of the dropout behaviour in YJTPs. Section 3 describes Projoven. Section 4 presents the empirical framework to evaluate dropout determinants at Projoven. Section 5 describes Projoven's dataset. Section 6 displays the results of our estimations. Finally, Section 7 presents our conclusions.

\section{YJTP dropout behaviour}

To understand the nature of the dropout phenomenon, it is necessary to assess its extent, to comprehend how the dropout decision is made, and to find out its determinants. This section discusses these items.

\section{Dropout extent}

YJTPs are popular in Latin America. They were idealised as a policy response to help the labour market insertion of economically disadvantaged youth in the 1990s. They provide skills to low-income groups, enabling them to deal with the challenges of globalisation. Since then, much has been written about the impact of YJTPs. They are regarded as effective policy interventions that produce positive returns on earnings and employment, particularly for women (Betcherman et al., 2004; Ibarrarán and Rosas, 2008). However, once trainees' level of completion is accounted for, different conclusions are reached. For the case of Projoven-Peru, Chong and Galdo (2006) suggest that completing the programme yields higher returns for trainees. Furthermore, Chacaltana et al. (2003) and de Crombrugghe et al. (2010) argue that the programme is not effective at all unless it is completed.

The dropout phenomenon is widespread in YJTPs. In Table 1 we observe that, with the exception of the Argentinean Proyecto Joven, which has a completion rate of $90 \%$, YJTPs in Latin America (Peru, Uruguay, Chile, Panama, and the Dominican Republic) experience completion rates below 77\%. Low completion rates are not just a Latin American phenomenon. Table 1 also displays some figures about YJTP performance in Germany and the United States, where the completion rates are lower than in some Latin American programmes.

All Latin American YJTPs share the two-step sequence design of classroom instruction and on-the-job training experience. In most cases, the policy planner finances job training centres to provide the training and to ensure that a quota of trainees is placed in firms for on-the-job training experience. Interestingly, the YJTPs listed in Table 1 present high completion rates (higher than 90\%) for the first phase of the training in comparison with the second phase of the training. 
This phenomenon can be explained by the twofold institutional arrangements. First, job training centres are bound by contract to ensure that a certain share of trainees participate in the on-the-job training experience after the classroom training phase. In Latin American countries, this percentage is $70 \%$, on average. However, in such cases as in Uruguayan, training centres must only comply with a $45 \%$ quota. This can explain why Projoven-Uruguay has the lowest completion rate among the examples compiled.

Second, another institutionally related explanation of the dropout phenomenon is the time gap between the two instructive phases. Santiago Consultores Asociados (1999) points out for the Chilean case that the transition from classroom training to the on-the-job training internship is not immediate. In many cases, weeks of delay discourage trainees from showing up. Such situations are also observed in Projoven-Peru.

\section{Dropout decision and its determinants}

In publicly funded YJTPs for economically disadvantaged individuals, all trainees are assumed to be able to graduate. In Projoven, for instance, training completion is not conditional on further tests or examinations. Trainees obtain a certificate of participation if they attend the courses and if they are present for the internship. This makes it difficult to extrapolate the results of the substantial literature on individuals dropout decision of post-secondary education. ${ }^{1}$ In the case of post-secondary education, completion (obtaining a degree/certificate) depends not only on attendance but on the capacity of the individuals to do so. In this study we borrow two elements from this literature which may apply to the analysis of dropout behavior in YJTPs: i) the presence of uncertainty about training returns; and ii) the existence of job opportunities.

First, uncertainty about the returns of YJTPs can lead individuals to modify their optimal length of training, even after enrolment. To be able to complete, the trainee must believe that it is worthwhile to do so. As such the expectancy about the returns of the training should be larger than the returns of her alternative activity. It is unlikely that trainees know beforehand the returns of the training. The only way the youngster can definitively determine whether the training is appropriate for her is by enrolling. It should be noted that well-known vocational training schools, which raise expectancy of high returns, rarely participate in Projoven. According to Projoven records, less than 5\% of the trainees receive instruction in well-known vocational training schools. In Peru, as in other developing countries, no ranking of vocational training institutions

\footnotetext{
${ }^{1}$ See Stratton, O'Toole, and Wetzel (2006) for a review of the conceptual and empirical work of this literature.
} 
exists. In addition, even if it existed, it is very unlikely that individuals at the bottom of the income distribution would be aware of it. Second, urgent job offers or individual shocks can also lead to a dropout decision. Youngsters can embark in training activities while waiting for a job offer.

A consequence of the trainees' uncertainty about training returns and future job offers is that before undertaking training, potential trainees ignore whether they are capable of completing the training or if it is worth doing so. We assume that an individual's decision to drop out is a consequence of a cost-benefit assessment made under uncertainty. In general, individuals remain in the programme as long as they feel it increases their chances to succeed in the labour market (Schochet, 1998; Heckman and Smith, 1999). In this fashion, the likelihood of completing the training (or of dropping out) depends on the individual opportunity costs and the expected outcomes of the training. The factors that affect trainees' opportunity costs and expected training outcomes can be classified into three categories: i) changes in labour market conditions, ii) the demographic characteristics of the individuals, and iii) programme content.

First, regarding changes in labour market conditions, Di Pietro (2004) and Peraita and Pastor (2000) argue that a shock that diminishes the unemployment rate of the region of residence encourages individuals to drop out of high school. When unemployment is low, more job offers may be available. In the case of YJTPs, job offers can increase trainees' opportunity costs of staying in training. Studies such as that of the Santiago Consultores Asociados (1999) for the Chilean case, Aedo and Nuñez (2004) for the Argentinean case, and Waller (2008) for the German case find that getting a job is the most common reason for dropping out of training. Market conditions also affect firms' training efforts (internship availability). On the one hand, recessions can increase firms' training efforts. The increased competition for sales in slack markets can induce business strategies that require more training. On the other hand, in a prolonged recession, expectations change and uncertainty increases. In these circumstances, the benefits of training are much more doubtful and the costs of training can only be reduced (Felstead and Green, 1996).

Second, individual characteristics, such as having children, having participated in training programmes before and/or having experienced unemployment influence dropout decisions by increasing the likelihood of leaving the programme (Waller, 2008). Impact evaluation literature offers plenty of examples that certain individual characteristics enhance training returns. For instance, women and individuals with no working experience benefit the most from YJTPs in Latin America (Betcherman et al., 2004; de Crombrugghe et al., 2010). These characteristics can make it worthwhile for some trainees to complete the training, but not for others. 
Finally, programme characteristics, mainly the courses and the quality of internships, can also affect dropout decisions. Hanushek et al. (2006) find this to be the case for primary school students in developing country settings. Highquality training modifies trainees' expectations about training returns. The training quality information is fully gathered by the trainee only once enrolled. Consequently, individuals modify their expected training outcomes during the training, which can lead them to drop out.

These factors that affect the opportunity cost and expected returns of undertaking training in the context of Projoven are taken into account in our estimations of the dropout decision determinants.

\section{Projoven-Peru}

Projoven's training courses are based on two main phases of instruction: classroom training and an on-the-job-training internship. Preceding its training activities, the programme encompasses three preparatory phases: course selection, targeting, and (self-) selection of participants and ECAP creaming. ECAP creaming is the process by which Projoven assigns trainees to courses and decides upon assignments when vacancies are limited.

The course selection process begins when Projoven launches a call for training providers. Institutions interested in participating in the programme must register in the database of training providers called RECAP (Registro de Entidades de Capacitación). To be registered in RECAP, potential ECAPs must have a valid licence from the Ministry of Education, possess proper facilities for teaching, and have a track record in vocational training. The ECAPs registered at RECAP are then invited to present course proposals. The courses must be at a low skill level, terminal (training should be sufficient to get a job and not merely complement other types of training/education), and, most importantly, labour demand oriented (there should be firms requiring workers with the training). The courses should be designed for no more than 15-25 students per classroom and last between 200 and 300 hours, with four to five contact hours per day spread over four or five days per week over three months. Proposals are selected based on a grading system. The most valued criteria for course selection are having the lowest unit cost per student and the ECAP's commitment to place at least $60 \%$ of the trainees in internships.

Targeting and self-selection follow. Potential enrolees are targeted based on a poverty map. Projoven's branch offices in the selected cities conduct campaigns to recruit from the targeted population. The target group consists of youths 
between the ages of 16 and 24, in poverty status, and with low educational attainment. The programme operator usually places newspaper ads and distributes flyers in strategically selected locations, and invites potential participants and their parents to information meetings.

Since programme participation is voluntary, participants self-select. Applicants who fulfil the requirements of age, poverty status, and low educational attainment are called back for a detailed evaluation of their eligibility. Potential trainees must fill in a socioeconomic evaluation form, which collects information about educational attainment, job training experience, labour status, family composition, and living space. Based on this information, Projoven calculates a poverty score. Only participants above a certain poverty threshold are accredited. $^{2}$

Finally, the ECAPs creaming process takes place. Accredited youths attend a meeting where they are informed about the available courses. The advantage of matching the courses closely with the participants' skills is pointed out. Next, the potential participants take a vocational test and choose three course options. The test assesses the applicant's capacity to execute simple arithmetic operations. The rationale for the test is to ascertain that potential trainees match the prerequisites of particular courses. For the most requested courses, Projoven sends up to three potential trainees for every vacancy available in each ECAP, based on trainee preferences and the results of the vocational test. Afterwards, the ECAP selects applicants based on interviews. No additional tests are allowed. Trainees not given their first option are reallocated according to their preferences in less sought after courses.

The actual training begins after these preparatory phases. The three-month classroom training phase consists of training courses in standard settings in the form of classes and workshops. Projoven assumes all tuition costs and pays the trainees stipends to cover transportation and food expenses. This amount can be marginally higher if the participant is a female parent, to encourage her participation. Participants are also covered by basic health insurance financed by the programme operator during the instruction period.

The final phase of the programme is a three-month on-the-job training internship. All participants who complete the classroom training, with attendance being the only requirement, are entitled, in principle, to start the on-the-job training phase. Almost all trainees complete the classroom training (98\%); however, the ECAPs fail to place around $20 \%$ of the trainees in internships. During the internship, the

\footnotetext{
2 To be accredited, participants should have more than 11 points in their poverty score. The poverty score is based on a number of proxies for poverty status, but excludes income.
} 
trainees should be under the supervision of a tutor. The assigned internship must consist of activities that complement the training received during classroom instruction. The programme operator supervises the development of this phase by interviewing the beneficiaries and participating firm managers. The ECAPs are responsible for the compatibility of the course content with the internship.

The aforementioned programme design has some implications in the trainees' dropout behaviour. First, since ECAPs compete for funding based on minimum costs, Projoven's supply of courses mixes high-quality courses and low-quality ones as both types are cost-efficient. Low-quality courses are less likely to be completed, since they can attach low employment chances as outcomes. Second, trainees are similar in eligibility characteristics. Yet, some elements of selfselection into the training can enhance programme returns and, consequently, affect the effort trainees make to complete the training. Third, since ECAPs are responsible for placing trainees in internships, trainee dropout behaviour is conditioned by the ECAPs' ability to find internship posts. Finally, the working conditions in internships can encourage trainees to drop out. A precarious working environment in the on-the-job training is likely to condition trainee continuance in the programme. The next section explains how these issues are taken into account when modelling the dropout likelihood of Projoven participants.

\section{Empirical framework}

This section presents two models to estimate the likelihood of dropping out of a Projoven internship. The choice of the models is based on the distribution of trainees by participation level. In Figure 1, we observe that almost all the trainees in the sample completed Projoven classroom training. However, not all trainees were placed in internships. Of the trainees who started the programme, $2.2 \%$ dropped out during the first month of classroom training, $20 \%$ were not placed in internships by their ECAPs, $21.7 \%$ dropped out of the training during the first two months of the internship, and 57\% completed the programme. This phenomenon of few dropouts in the classroom phase occurs in virtually all the Latin American programmes as previously mentioned. We suspect that, in addition to the time gap between phases and the quota of internships, in the case of Projoven it may has also to do with the way training providers are paid. ECAPs are financially compensated by the training operator when trainees complete at least the classroom phase. This can encourage ECAPs to monitor closely that trainees attend the classroom training.

The first model, a probit model with sample selection correction (van de Ven and van Praag, 1981), tests and corrects for the possibility of selection into internship. 
If trainees placed in internships are not a random sample of all trainees, the parameters estimating the dropout propensity can be biased. It could be the case that trainees with certain characteristics are more likely to be placed in internships.

The second model, a multinomial probit, distinguishes different exit routes. Trainees can quit the programme because of a job offer or because of another reason that leads them to unemployment or inactivity. Our second model tests whether the trainees who leave the programme for a job are different from those who leave the programme and end up unemployed or inactive.

Model 1: Probability of dropping out of a Projoven internship (probit model with sample selection)

We can only observe the decision to drop out from a Projoven internship for those trainees placed in internships. To account for selection into internship, we propose a probit model with sample selection. Our dependent variable follows a process such as the one of Figure 2.

This empirical strategy assumes that an individual $(i)$ decides to drop out based on the expected utility for doing so $\left(U_{i}^{*}\right)$. When a trainee drops out, we specify the individual's expected utility as follows:

[Eq. 1] $U_{i}^{*}=X_{i}^{\prime} \beta_{1}+v_{i 1}$

with $\beta_{1}$ a vector of unknown parameters and $v_{i 1}$ an unobservable stochastic error distributed standard normally. Here, $X_{i}$ includes covariates such as individual characteristics (age, household size, sex, marital status, parental status, household income, years of schooling, previous training courses, and work experience), city of residence, and characteristics of the internship (written contract in the internship). Table 2 describes the variables included in our estimations. Implicitly, our specification assumes away a potential endogeneity of the contract variable. All trainees are supposed to be given a written contract during the internship, but this contract is not offered to all. Unobservables can affect both the likelihood of dropping out and the likelihood of being given a written contract. Unfortunately, we lack additional explanatory variables (to serve as instruments) to test for potential endogeneity. We acknowledge the limitation of our study in this respect.

Utilities are obviously unobservable, but we do observe the decision to drop out or stay in the programme. Formally, consider a variable $D_{i}$, where $D_{i}=1$ when 
the trainee drops out, and $D_{i}=0$ otherwise. Then, $D_{i}=0$ if $U_{i}^{*} \leq 0$ and $D_{i}=1$ if $U_{i}^{*}>0$. We model the probability of dropping out of the internship as

[Eq. 2] $\operatorname{Pr}\left[D_{i}=1\right]=\operatorname{Pr}\left[U_{i}^{*}>0\right]=\operatorname{Pr}\left[X_{i}^{\prime} \beta_{1}+v_{i 1}>0\right]$.

Recall that the likelihood of dropping out of a Projoven internship is only observed for those trainees who were placed in internships. Let $H_{i}$, a dichotomous variable, denote the indicator of selection into an internship when $H_{i}=1$. Thus, the probability that $D_{i}$ is observed is given by

[Eq. 3] $\operatorname{Pr}\left[H_{i}=1\right]=\operatorname{Pr}\left[Z_{i}^{\prime} \beta_{2}+v_{i 2}>0\right]$,

where $\beta_{2}$ is a vector of unknown parameters, $v_{i 2}$ is an unobservable stochastic error distributed standard normally, and $Z_{i}$ is a vector containing almost all the variables included in $X_{i}$ except for the variable 'contract', which is only observed during the internship. Note that $Z_{i}$ also contains ECAP characteristics such as number of students per course, course workload, share of teachers with more than five years of experience, whether or not the trainee followed a production-oriented course, and dummy variables about the type of ECAP. These variables are excluded from the response equation. The rationale is that these variables are intrinsically related to the first part of the training instruction (classroom phase). The second part of the training (internship phase) is carried out in a training firm different from the ECAP. Therefore, the factors that affect the trainees' decision to drop out of the internship must be related to individual characteristics and internship-related variables rather than ECAP course-related variables. In addition, ECAP course features may reflect the ability to find internships. The (in) exclusion of type of ECAP in the response equation does not modify the estimates of the other coefficients in the regression.

To estimate the likelihood of dropping out of a Projoven internship conditional on being placed in a training firm (internship), we assume that $\left(v_{i 1}, v_{i 2}\right)$ are bivariate normal for all $i$, with

[Eq. 4] $v_{i 1} \sim N(0,1)$,

[Eq. 5] $v_{i 2} \sim N(0,1)$,

[Eq. 6] $\operatorname{corr}\left(v_{i 1}, v_{i 2}\right)=\rho$.

If $\rho \neq 0$, estimates of [Eq. 2] will be biased unless we account for the selection. Eventually, the usual tests for independence of the structural equations will be performed to assess the robustness of the estimations. 
Model 2: Probability of dropping out of a Projoven internship, given different exit routes (multinomial probit model)

In the data of Projoven's sixth public call, it is possible to identify three exit routes from a Projoven internship: i) completion, ii) dropping out of training for a job, and iii) dropping out of training into unemployment or inactivity. The exit routes are represented by the categorical scalar $d_{i}$, which values representing completers (1), dropouts to a job (2) and dropouts to unemployment (3) (See Figure 3).

The previous section implicitly assumes that the effects of the explanatory variables are homogeneous across exit routes. We aim to estimate whether the effect of the explanatory variables included in the dropout model differ, given that $d_{i}=m$, where $m=1,2$, or 3 . The multinomial probit approach is used, since we assume that all trainees face the same choice set once they are placed in internships. Hence, we specify the utility of choosing the exit route $m=1,2,3$ as

[Eq. 7] $U_{i m}^{*}=X_{i}^{\prime} \alpha_{m}+\xi_{i m}$,

where $X_{i}$ is defined as in the previous model. Associated with $X_{i}$ are the three vectors of regression coefficients $\alpha_{1}, \alpha_{2}$ and $\alpha_{3}$. The error terms $\xi_{i 1}, \xi_{i 2}$, and $\xi_{i 3}$ are assumed independent and standard normal. Trainee $i$ will choose the alternative $k$ in which the trainee's level of utility $U_{i k}^{*}>U_{i l}^{*}$ for all $l \neq k$. For $l \neq k$, let

$$
\begin{aligned}
& \text { [Eq. 8] } v_{i m}=U_{i l}^{*}-U_{i k}^{*} \\
& \quad=X_{i}^{\prime}\left(\alpha_{l}-\alpha_{k}\right)+\xi_{i l}-\xi_{i k} \\
& =X_{i}^{\prime} \gamma_{m}+\varepsilon_{i m},
\end{aligned}
$$

where $m=l$ if $l<k$ and $m=l-1$ if $l>k$, so that $m=1,2$. Notice that $\varepsilon_{i}=\left(\varepsilon_{i 1}, \varepsilon_{i 2}\right) \sim \operatorname{MVN}(0, \Sigma)$, where $\Sigma=\left(\begin{array}{ll}2 & 1 \\ 1 & 2\end{array}\right)$. The probability that the alternative $k$ is chosen is

$$
\begin{aligned}
& \text { [Eq. 9] } P_{i k}=\operatorname{Pr}\left(d_{i}=k \mid X_{i}\right)=\operatorname{Pr}\left(v_{i 1} \leq 0, v_{i 2} \leq 0\right) \\
& =\operatorname{Pr}\left(\varepsilon_{i 1} \leq-X_{i}^{\prime} \gamma_{1}, \varepsilon_{i 2} \leq-X_{i}^{\prime} \gamma_{2}\right) .
\end{aligned}
$$

This probability (on which the likelihood function is based) involves a twodimensional integral that is difficult to compute. Because of the exchangeable 
correlation structure of $\Sigma$, Dunnett's (1989) reduction of the multidimensional integral to a single dimension is utilised. Gaussian quadrature is used to approximate this integral. ${ }^{3}$ For purposes of identification, $d_{i}=1$ (training completion) is the base category $\left(\alpha_{1}=0\right)$. Therefore, the remaining set of coefficients $\alpha_{2}, \alpha_{3}$ will measure the differences relative to the completer's group.

\section{Data}

The dataset of Projoven's sixth public call includes a baseline survey, conducted in November 1999 (two to three months before the programme), and three followup comparison surveys, one six months after the programme (May 2001), one 12 months after (November 2001), and one 18 months after (May 2002). ${ }^{4}$ We use only the baseline survey as a source of information about trainees' individual characteristics. Additionally, we utilise Projoven administrative records to add the ECAP's characteristics as explanatory variables. The dataset of Projoven's sixth public call consists of 1,014 individuals. We excluded from the sample trainees who dropped out during the first month of classroom training. As a consequence, our sample comprises 992 trainees.

Since Projoven has a fixed length of participation, we distinguish two types of individuals: those who complete the training and those who do not. Among those who do not complete the training, we identify three categories: involuntary ending (not placed in internships), dropping out of on-the-job training for a job, and dropping out of on-the-job training into unemployment or inactivity. Projoven administrative records do not include the reason for dropping out (job offer or unemployment). The reason for dropping out was inferred from matching labour market conditions and dropout timing. Thus, individuals who were working during the month in which they dropped out or a month later are considered to have dropped out for a job; otherwise they are regarded as having dropped out into unemployment or inactivity.

Table 3 displays the summary statistics. We observe that trainees, both completers and dropouts, are similar in eligibility-related variables such as age, household income per capita, and years of schooling. Table 3 also shows that the differences between completers and dropouts regarding household size, gender, marital status, number of children, and participation in another training course are not statistically significant. In addition, a higher share of individuals without

\footnotetext{
${ }^{3}$ We use the Stata canned command mprobit to estimate the multinomial probit model.

${ }^{4}$ Not all internships start immediately after the classroom training. The last internship was completed six months before May 2001.
} 
working experience is observed among dropouts in comparison with the completers.

Regarding the city of residence, the proportion of dropouts with respect to completers is higher in Lima than in the rest of the cities; however, we must note that Lima has a higher share of trainees. A more detailed picture about dropout rates per city is given in Table 4. Table 4 shows that Arequipa, Cusco, and Trujillo have better performance in terms of completion with respect to Lima and Chiclayo. In terms of dropout exit routes, involuntary dropouts are, in statistical terms, as important as those who drop out for a job. Only $8 \%$ of the trainees drop out into unemployment or inactivity. Nevertheless, this proportion increases up to $17 \%$ in Chiclayo, where the involuntary dropout rate is also the highest $(41 \%)$, double the total's average (18.5\%).

With respect to ECAP characteristics, we observe significant differences regarding students per course, course workload, and cost per student per hour. ECAP effectiveness is lower for trainees who drop out involuntarily. The ECAPs of completers have lower numbers of courses than the ECAPs of dropouts. The share of teachers with more than five years of experience is higher in the ECAPs of dropouts. Completers represent a higher share than dropouts in alternative indicators of training quality such as the share of trainees with a written contract in the internship. This indicator is also evidence of the low enforcement power of the programme operator. Firms must hire trainees under training contracts and pay them the minimum wage. Only the Projoven branch offices of Lima and Chiclayo collected this information directly from the trainees. ${ }^{5}$

With respect to the types of courses, we observe that dropouts (for a job or into unemployment or inactivity) represent a higher share in industry-oriented courses, whereas completers and involuntary dropouts represent a higher share in service-oriented courses. Regarding the type of training centres, Table 3 shows that completers represent a higher share than dropouts in centres for vocational training (CEOs), firms, and non-governmental organizations (NGOs), whereas dropouts have a greater presence in institutes for tertiary technical education (ISTs), universities, and vocational training centres sponsored by economic sector guilds and others.

\footnotetext{
${ }^{5}$ The inclusion of the written contract variable does not affect the coefficient estimation of the rest of the variables. As contract information is not available in Arequipa, Cusco, and Trujillo, this variable is coded as zero for trainees in those cities. Alternative models were run excluding this variable, and the coefficients' signs and significance were not altered. When running the model only for Chiclayo and Lima, the same conclusions apply.
} 


\section{Results}

This section shows the results of the estimation of the probability of dropping out of a Projoven internship. Two models are presented: a probit model with sample selection (Model 1) and a multinomial probit model (Model 2). For Model 1 , we present the results of the two parts of the model: the probability of a Projoven internship placement (selection equation) and the probability of dropping out of a Projoven internship (response equation). For Model 2, the probability of dropping out of a Projoven internship given different exit routes is estimated.

\section{Model 1 - selection equation: Probability of a Projoven internship placement}

Table 5 displays the selection model indicating the likelihood of a trainee being placed in an internship. The results suggest that there are no discrimination practices in trainee placement in internships, at least based on observables. Variables such as age, household size, gender, having children, income, schooling, previous work experience, and previous participation in a training course are not significant in the model.

The insignificant coefficient of individual-related variables may indicate that it is the capacity of the ECAP that determines internship placements. In fact, in the selection model, ECAP-related variables explain the trainees' likelihood of being placed in an internship. Higher costs per student increase the likelihood that a trainee is placed in an internship. Finding internships involves more costs than only providing classroom training. ECAPs that invest more per trainee are apparently more successful at finding internships. In addition, ECAPs that teach more courses face more difficulties finding internships for their trainees. In our estimates, a larger number of students per course increases the likelihood of being placed in an internship. Usually, it is thought that the lower the number of students in a class, the better the instruction. The course selection criteria, which mix low-quality courses and efficient ones, may be more important in this case. Since the programme operator rewards low-cost proposals, ECAPs try to offer as many courses as possible. Nevertheless, more efficient ECAPs can compensate for these costs by placing more students in each course. The marginal cost of placing an additional student may be reduced, given economies of scale.

The model also indicates that studying industry-oriented courses, relative to service-oriented ones, increases the probability of a trainee being placed in an internship. Perhaps these courses are relatively more in demand in the labour market. Other variables, although not statistically significant, provide an interesting explanation of internship placement. A higher share of instructors with more than five years of experience increases the likelihood of being placed 
in an internship. Perhaps old instructors have more contacts in the labour market. Additionally, an ECAP's effectiveness (share of trainees per ECAP working six months after the training) seems to work as a credential or indicator of reputation for the ECAP, given the positive sign of the coefficient.

It is not possible to draw any particular conclusions about the type of training centre. Both the NGO and CEO dummy coefficients are positive and statistically significant. This could imply that these types of training centres are most likely to place trainees in internships. However, low-quality ECAPs outnumber highquality ECAPs in Projoven even within the seven categories considered in Table 2 (Chacaltana et al., 2003; Chong and Galdo, 2006).

Regarding the city dummies, only Arequipa is significant. It seems that ECAPs in Arequipa are more successful in placing trainees in internships (with respect to Lima). It may be easier for ECAPs to place trainees in a booming environment. For instance, in 2000, the year of reference, the growth rate of the gross domestic product of Arequipa was relatively higher than Lima's (3.5\% versus 2.4\%, respectively). More internship vacancies may be available under those circumstances.

Summing up, there is no evidence of discrimination in trainees' placement into internship. It seems that the ECAPs' features rather than trainee characteristics influence the likelihood of placement in internships. ${ }^{6}$ In addition, regional characteristics (represented by city dummies) also play a role. The environment where the training is carried out affects the ECAPs' capacity to place trainees in internships.

Model 1 - response equation: Probability of dropping out of a Projoven internship

Table 6 displays the maximum likelihood estimations of the probit model with probit sample selection correction [A], an independent probit model [B], a linear probability model (LPM) with probit sample selection correction [C], and a linear probability model with logit sample selection correction [D]. ${ }^{7}$ The last three models were included as a matter of comparison. In almost all the cases, the parameters coincide in sign; nonetheless, small differences are presented in some

\footnotetext{
${ }^{6}$ This model estimates robust clustered standard errors to account for intra-ECAP correlation.

${ }^{7}$ Lee (1983) suggests a technique to use a logit regression in the two-step Heckman procedure for sample selection correction. This method estimates the selection equation using a logit model. Then, it uses the individual probabilities predicted by the model. Using the inverse cumulative distribution function of the normal distribution, these individual probabilities are translated into the form they would have had had they been computed on the basis of a probit model. Finally, these quasi-probit scores are used to compute the inverse Mills ratio the same way as when using a probit selection model.
} 
of the coefficients' magnitude. The coefficients of models [B], [C], and [D] resemble those of model [A]. In interpreting and discussing the estimated marginal effects, we will further concentrate on model [A].

A positive correlation $(\hat{\rho})$ indicates the overrepresentation of trainees, with unobserved characteristics making them more likely to be placed in internship. We find that there is indeed a positive correlation $(\hat{\rho}=0.300)$ between the selection equation (likelihood of internship placement) and the response equation (dropout likelihood); however, it is not significant. We conclude that there is no clear evidence of sample selection. Similarly, models [C] and [D] provide little evidence of systematic sample selection.

In the response equation, we note that demographic variables such as age, female, years of schooling, children, marital status, and household income are not statistically significant. Dropouts and completers are similar in these variables, since they determine whether individuals are eligible or self-selected into the programme. Similar results in this respect are found in Waller (2008). Interestingly, although not statistically significant, prior experience with training courses diminishes the likelihood of dropping out of a Projoven internship. Trainees who have followed vocational training courses in the past may be more trainable for training firms. In addition, trainees with prior vocational experience may have relatively higher marginal returns, making the option to quit less attractive.

It seemed that trainees in larger households are more likely to drop out. Trainees in larger households may be more constrained by financial resources. It is argued that the poor have a higher discount rate and are, therefore, short-run focused in their decision making. Although completing training can provide higher returns in the long run, economically disadvantaged trainees feel tempted to drop out if a job opportunity presents itself, even if it is not a good one. Salaries are paid at the end of the month during the internship. Alternative jobs in the informal sector are usually paid daily, but not necessarily with higher compensations.

The model suggests that regional differences, with respect to Lima, negatively affect trainees' dropout decisions. Poverty rates in urban areas are higher for Arequipa, Chiclayo, Cusco, and Trujillo than for Lima (39\%, 50\%, 54\%, 38\%, and $34 \%$, respectively, for the reference year 2000). The opportunity costs of trainees outside Lima seem to be lower, diminishing the likelihood of trainees dropping out.

A crucial variable affecting the likelihood of dropping out is the presence of a written contract in the internship. Trainees with written contracts are less likely to drop out. Since it is possible that firms hire trainees after the three-month 
internship, the presence of a contract may encourages trainees to stay and complete the training. The absence of a written contract could be evidence of precarious working conditions. In the Peruvian labour market (formal or informal), working with no contract implies no social security coverage, long hours, and an unsafe work environment (Chacaltana, 2006). Santiago Consultores Asociados (1999) for the Chilean case and Aedo and Nuñez (2004) for the Argentinean case surveyed dropouts on their reasons for quitting. Most of the dropouts argued that they worked under precarious conditions and in some cases the internship content was not related to the classroom training.

Finally, in Table 6 we also note that, although not statistically significant, the effectiveness of the training reduces the likelihood of dropping out. The fact that ECAPs are successful, in terms of their graduates finding work, encourages trainees to continue and complete the training.

Model 2: Probability of dropping out of a Projoven internship through different exit routes

The estimates of the multinomial probit model are displayed in Table 7. Contrary to the previous specification, this model allows the explanatory variable effects to differ by exit route. In this specification, we account for two different exit routes: i) dropping out of a Projoven internship for a job and ii) dropping out of a Projoven internship into unemployment or inactivity. These are compared with respect to programme completion (base category). This model disregards the selection process, since the hypothesis of sample selection was rejected in the previous section under different specifications.

In the component of the model concerning dropping out for a job, we observe that trainees with no work experience are less likely to drop out. Perhaps for these trainees the internship, as a working experience, is more valuable. In the market for low-skilled jobs, experience is valued the most. In this case, training can serve as a screening device to identify the productivity of unskilled youngsters. This result may also be related to the returns of the programme. De Crombrugghe et al. (2010) find that trainees with no work experience have higher returns from their training. Thus, trainees would not drop out for a job when the returns from doing so are lower. In addition, trainees with no work experience may not receive many job offers. Females are also less likely to drop out for a job. This could be related to the expected effects of the programme. Authors such as Betcherman et al. (2004) and Ibarrarán and Rosas (2007) find that YJTPs in Latin America yield higher returns, in terms of wages and employment, for women. Interestingly, although not statistically significant, females parents are less likely to drop out for a job. This seems to be an effect of the extra 
stipends for individuals in that category. As in the probit model, trainees in larger household are more likely to drop out for a job.

In the component of the model concerning dropping out into unemployment, it seems that trainees lacking work experience are more likely to drop out. Individuals with no work experience are less employable. Consequently, when they drop out, they usually find themselves unemployed. Waller (2008) finds a similar effect. This may also be the case for women, particularly those with children (although the latter is not a significant factor). The group of individuals who drop out of YJTPs into unemployment includes trainees who exclude themselves from the training due to random shocks, such as disease or a relative's death (Santiago Consultores Asociados, 1999; Aedo and Nuñez, 2004). Unfortunately, those variables are not reflected in the observable characteristics included in the regression analysis.

There are some variables that similarly affect both exit routes in the model. The marginal effects of the city dummies are statistically significant and negative. As in the previous specification, it seems that regional differences with Lima decrease the dropout likelihood. It is less likely that trainees receive jobs offers in unfavourable economic conditions. In both exit routes, working an internship under the regulation of a written contract discourages trainees to drop out. This may indicate the firm's commitment to training activities. Hiring trainees informally, with no written contract, suggests that the training firm is using trainees as cheap labour. Consequently, trainees with no contract do not find it worthwhile to complete the internship.

In sum, trainees who are males and who have prior work experience are less likely to drop out into unemployment, but more likely to drop out for another job. This may be why the effects of these variables are found to be not significant in Model 1, which does not distinguish exit routes. Similarly, the effect of household size is found to be positive and significant in Model 1 and in the drop out for a job component of Model 2, and negative and insignificant in the drop out into unemployment component of Model 2. Perhaps, Model 1 comprises the average effect of the two components of Model 2. This shows how important it is to distinguish between exit routes. It seems that trainees who drop out for a job are different from those who drop out into unemployment. Nevertheless, Model 1 is important to show that there is no evidence of selection into internship placement. In addition, precarious working conditions in the internship (no written contract) discourage trainees from continuing with the training, irrespective of the model or exit route. Both Model 1 and Model 2 address how crucial regional differences are in modifying trainees' expectations and opportunity costs to continue training. 


\section{Conclusions}

Some studies suggest that YJTPs are more effective when completed (Mealli et al., 1996; Chacaltana et al., 2003; Chong and Galdo, 2003; de Crombrugghe et al., 2010) or the longer the trainee is exposed to the training (Kluve et al., 2007; Flores-Lagunes et al., 2007). If training is effective conditional on completion, it is crucial to find out the reasons why trainees drop out. In this paper we analyse the determinants of trainees' dropout decisions in the Peruvian YJTP Projoven. We model the dropout behaviour in two ways. First, we use a probit model with sample selection to evaluate the likelihood of dropping out of a Projoven internship conditional on internship placement. Second, to consider different exit routes of the programme, we utilise a multinomial probit model. This model explains the likelihood of dropping out of Projoven for a job and into unemployment or inactivity, with respect to that of completing the programme. In our models, we test whether dropout is due to i) trainee characteristics, ii) regional context differences, or iii) training characteristics. We reach four general conclusions.

First, the effects of individual characteristics vary across exit routes. When only one exit route is considered, only being a member of a larger household seems to be relevant. However, when more exit routes are considered, we find that trainees who drop out for a job are different from those who drop out into unemployment. Males and individuals with work experience are more likely to drop out for a job, whereas they are significantly less likely to drop out into unemployment or inactivity. These results confirm two previous findings. First, in many YJTPs in Latin America, female trainees benefit the most from training (Betcherman et al., 2004). Second, in the case of Projoven, trainees who do not have work experience benefit the most from training completion (de Crombrugghe et al., 2010). Thus, females and trainees with no work experience are most likely to be unemployed if they are not in the programme. The programme's effects could be enhanced if more women and individuals with no work experience were interested; however, some measures (incentives) must be implemented by the programme operator so that these individuals do not drop out.

Second, regional differences play an important role in explaining dropout behaviour. In both models, the comparison of small cities with Lima suggests that where fewer opportunities are available for youngsters, the dropout likelihood decreases. It seems that Projoven is seen as an alternative when jobs are unavailable. 
Third, classroom training characteristics and internship conditions are crucial in explaining dropout behaviour. In the selection equation of Model 1, we observe that an ECAP's capacity determines trainee placement in internships. This could be why the hypothesis of selection into internship is rejected. In addition, working with no written contract (i.e., under precarious conditions) discourages trainees from completing the programme despite the exit routes. Consequently, training content and its quality affect the dropout likelihood. This is an important result, since training content and quality affect not only the dropout likelihood, but also the labour market outcomes of the trainees.

Finally, our results suggest that trainees' dropout decisions follow a rational pattern. Trainees stay in the programme as long as they perceive evidence that it is worth doing so. First, since women and individuals with no work experience are most likely to benefit from the course, they are also less likely to drop out. Second, in cities where fewer job opportunities are available (in comparison with Lima), trainees are also less likely to drop out. Finally, when the training conditions indicate chances of being hired on a permanent basis or the training firm is committed to the training activities (having a written contract), trainees are also less likely to drop out.

Finding out what drives trainees to complete or drop out of YJTPs is important because it helps policy planners enhance the outcomes of their programmes. The evidence presented in this paper implies that economically disadvantaged youngsters need to be provided with not only classroom training and internships, but also the motivation and guarantee that completing the training will pay off. Therefore, a more rigorous process of selecting training providers and more effective enforcement mechanisms are necessary to rule out internships that offer precarious conditions (in terms of the lack of contracts) and to ensure highquality training courses, including internship placements. Hence, YJTPs such as Projoven could achieve better results in terms of completion rates and training outcomes. 


\section{References}

Aedo, C., and S. Nuñez, 2001. The impact of training policies in Latin America and the Caribbean: The case of Programa Joven. Working Paper Series Instituto Latinoamericano de Doctrina y Estudios (ILADES)/Georgetown University.

Betcherman, G., K. Olivas, and A. Dar, 2004. Impacts of active labour market programs: New evidence from evaluations with particular attention to developing and transition countries. World Bank Social Protection Discussion Paper 0402.

Card, D., P. Ibarraran, F. Regalia, D. Rosas, and Y. Soares, 2007. The labor market impacts of youth training in the Dominican Republic: Evidence from a randomized evaluation. NBER Working Paper 12883.

Chacaltana, J., 2006. Empleo para los Jóvenes. Centro de Estudios para el Desarrollo (CEDEP) - Comisión Económica para América Latina (CEPAL) - Cooperación Técnica Alemana (GTZ), Lima.

Chacaltana, J., G. Guerrero, H. Espinoza, and O. Pain, 2003. ¿Qué funciona y qué no funciona en Projoven?: Una evaluación de los procesos de capacitación y medición de impacto. Inter American Development Bank Report.

Chong, A., and J. Galdo, 2006. Does the quality of training programs matter? Evidence from bidding processes data. IZA Discussion Paper 2202.

de Crombrugghe, D., H. Espinoza, and H. Heijke, 2010. Job training programmes with low completion rate: The case of Projoven-Peru. Working Paper ROA-RM2010/4, Research Centre for Education and the Labour Market (ROA), Maastricht.

Di Pietro, G., 2004. The determinants of university dropout in Italy: A bivariate probability model with sample selection. Applied Economics Letters 11 (3), 187191.

Dunnett, C. W., 1989. Algorithm AS 251: Multivariate normal probability integrals with product correlation structure. Journal of the Royal Statistical Society, Series C 38, 564-579.

Felstead, A., and F. Green, 1996. Training implications of regulation compliance and business cycles. In A. L. Booth and D. J. Snower (eds.), Acquiring Skills: Market Failures, Their Symptoms and Policy Responses. Cambridge University Press, Cambridge. 
Flores-Lagunes, A., A. Gonzalez, and T. C. Neumann, 2007. Estimating the effects of length of exposure to a training program: The case of Job Corps. IZA Discussion Paper 2846.

Hanushek, E. A., V. Lavy, and K. Hitomi, 2006. Do students care about school quality? Determinants of dropout behaviour in developing countries. NBER Working Paper 12737.

Heckman, J. J., N. Hohmann, J. Smith, and M. Khoo, 2000. Substitution and dropout bias in social experiments: A study of an influential social experiment. Quarterly Journal of Economics 115 (2), 651-694.

Heckman, J. J., and J. A. Smith, 1999. The pre-program earnings dip and the determinants of participation in a social program: Implications for simple program evaluation strategies. NBER Working Paper 6983.

Heckman, J. J., J. A. Smith, and C. Taber, 1998. Accounting for dropouts in evaluation of social programs. Review of Economics and Statistics 80 (1), 1-14.

Ibarrarán, P., and D. Rosas, 2007. Impact evaluation of a labour training program in Panama. Inter-American Development Bank Working Paper.

Ibarrarán, P., Rosas, D., 2008. Evaluating the impact of job training programs in Latin America: Evidence from IDB funded operations. Inter-American Development Bank Working Paper.

Kluve, J., H. Schneider, A. Uhlendorff, and Z. Zhao, 2007. Evaluating continuous training programs using the generalized propensity score. IZA Discussion Paper 3255.

Lee, L.-F., 1983. Generalized econometric models with selectivity. Econometrica $51(2), 507-512$.

Mealli, F., S. Pudney, and J. Thomas, 1996. Training duration and post-training outcome: A duration-limited competing risks model. Economic Journal 106 (435), $422-433$.

O'Toole, D. M., L. S. Stratton, and J. N. Wetzel, 2006. Are the factors affecting dropout behavior related to initial enrollment intensity for college undergraduates? IZA Discussion Paper 1951. 
Peraita, C., and M. Pastor, 2000. The primary school dropout in Spain: The influence of family background and labour market condition. Education Economics 8 (2), 157-168.

Santiago Consultores Asociados, 1999. Evaluación ex post Chile Joven Fase II. Santiago Consultores Asociados, Santiago de Chile.

Schochet, P. Z., 1998. National Job Corps study: Eligible applicants' perspectives on Job Corps outreach and admissions. Report, Mathematica Policy Research, Princeton, NJ.

van de Ven, W. P. M. M., and B. M. S. van Praag, 1981. The demand of deductibles in private health insurance: A probit model with sample selection. Journal of Econometrics 17 (2), 229-252.

Waller, M., 2008. Further training for the unemployed - What can we learn about dropouts from administrative data? FDZ Report 4/2008, The Research Data Centre (FDZ) of the German Federal Employment Agency (BA). 
Table 1.

Youth job training programmes and completion rates.

\begin{tabular}{|c|c|c|c|c|}
\hline Programme & Country & Year & $\begin{array}{c}\text { Completion } \\
\text { rate }\end{array}$ & Source \\
\hline Projoven ${ }^{a}$ & Peru & $\begin{array}{c}1996- \\
2005\end{array}$ & $60 \%$ & de Crombrugghe et al. (2010) \\
\hline Projoven ${ }^{b}$ & Uruguay & $\begin{array}{c}2004- \\
2005\end{array}$ & $51 \%$ & Projoven survey (2006) \\
\hline Chile Jovenc & Chile & $\begin{array}{c}1996- \\
1999\end{array}$ & $74 \%$ & $\begin{array}{l}\text { Santiago Consultores } \\
\text { Asociados (1999) }\end{array}$ \\
\hline Proyecto Joven & Argentina & $\begin{array}{c}1996- \\
1997\end{array}$ & $90 \%$ & Aedo and Nuñez (2004) \\
\hline Procajoven & Panama & 2005 & $77 \%$ & Ibarrarán and Rosas (2007) \\
\hline Juventud y empleo & $\begin{array}{l}\text { Dominican } \\
\text { Republic }\end{array}$ & 2004 & $60 \%$ & Card et al. (2007) \\
\hline Training programmes ${ }^{\mathrm{d}}$ & Germany & $\begin{array}{l}2000- \\
2002\end{array}$ & $69 \%$ & Kluve et al. (2007) \\
\hline $\begin{array}{l}\text { National Job Training } \\
\text { Partnership Act (JTPA)e }\end{array}$ & USA & $\begin{array}{c}1987- \\
1989\end{array}$ & $58 \%$ & Heckman et al. (2000) \\
\hline
\end{tabular}

a The figure corresponds to the average completion rate of the first 13 public calls.

b Only the 10th public call.

c Phase 2. The figures belong to the 'training and job experience' component.

d Sample of only men. Includes 'occupation-specific training programmes' and 'general training programmes'.

e Only classroom training. In this case dropouts are individuals who enrolled in the programme but did not show up. 
Table 2.

Description of variables.

\begin{tabular}{|c|c|}
\hline Variable & Description \\
\hline \multicolumn{2}{|l|}{ Demographic characteristics } \\
\hline Age & Age in years \\
\hline Household size & Household size (number of people) \\
\hline Female & 1 female; 0 male \\
\hline Married & 1 married or living as a couple; 0 otherwise \\
\hline Household income & $\begin{array}{l}1 \text { has a child; } 0 \text { otherwise } \\
\text { Ln of household income per capita in Peruvian currency units (without trainee } \\
\text { income) }\end{array}$ \\
\hline Years schooling & Years of schooling \\
\hline Previous job training course & 1 training course other than Projoven (prior to training); 0 otherwise \\
\hline Work experience & 1 no work experience prior to the training; 0 otherwise \\
\hline \multicolumn{2}{|l|}{ City dummies } \\
\hline Arequipa & 1 lives in Arequipa; 0 otherwise \\
\hline Chiclayo & 1 lives in Chiclayo; 0 otherwise \\
\hline Cusco & 1 lives in Cusco; 0 otherwise \\
\hline Lima & 1 lives in Lima; 0 otherwise \\
\hline Trujillo & 1 lives in Trujillo; 0 otherwise \\
\hline \multicolumn{2}{|l|}{ ECAP characteristics } \\
\hline Effectiveness & Proportion of trainees working six months after the training \\
\hline Number & ECAP's number of courses \\
\hline Students & Students per course \\
\hline Workload & Course workload (hours) \\
\hline Cost & Cost per student per hour (in Peruvian currency units) \\
\hline Teachers & Proportion of teachers with more than five years of experience (\%) \\
\hline Industry & 1 industry-oriented course; 0 service-oriented course \\
\hline \multicolumn{2}{|l|}{ ECAP type } \\
\hline CEO & 1 centre for vocational training; 0 otherwise \\
\hline Firm & 1 firm; 0 otherwise \\
\hline IST & 1 IST; 0 otherwise \\
\hline NGO & 1 NGO; 0 otherwise \\
\hline Guild & 1 vocational training centre sponsored by an economic sector guild; 0 otherwise \\
\hline University & 1 university; 0 otherwise \\
\hline Other & 1 other (high school, church); 0 otherwise \\
\hline \multicolumn{2}{|l|}{ Internship characteristics } \\
\hline Contract & 1 on-the-job training with written contract; 0 otherwise \\
\hline
\end{tabular}




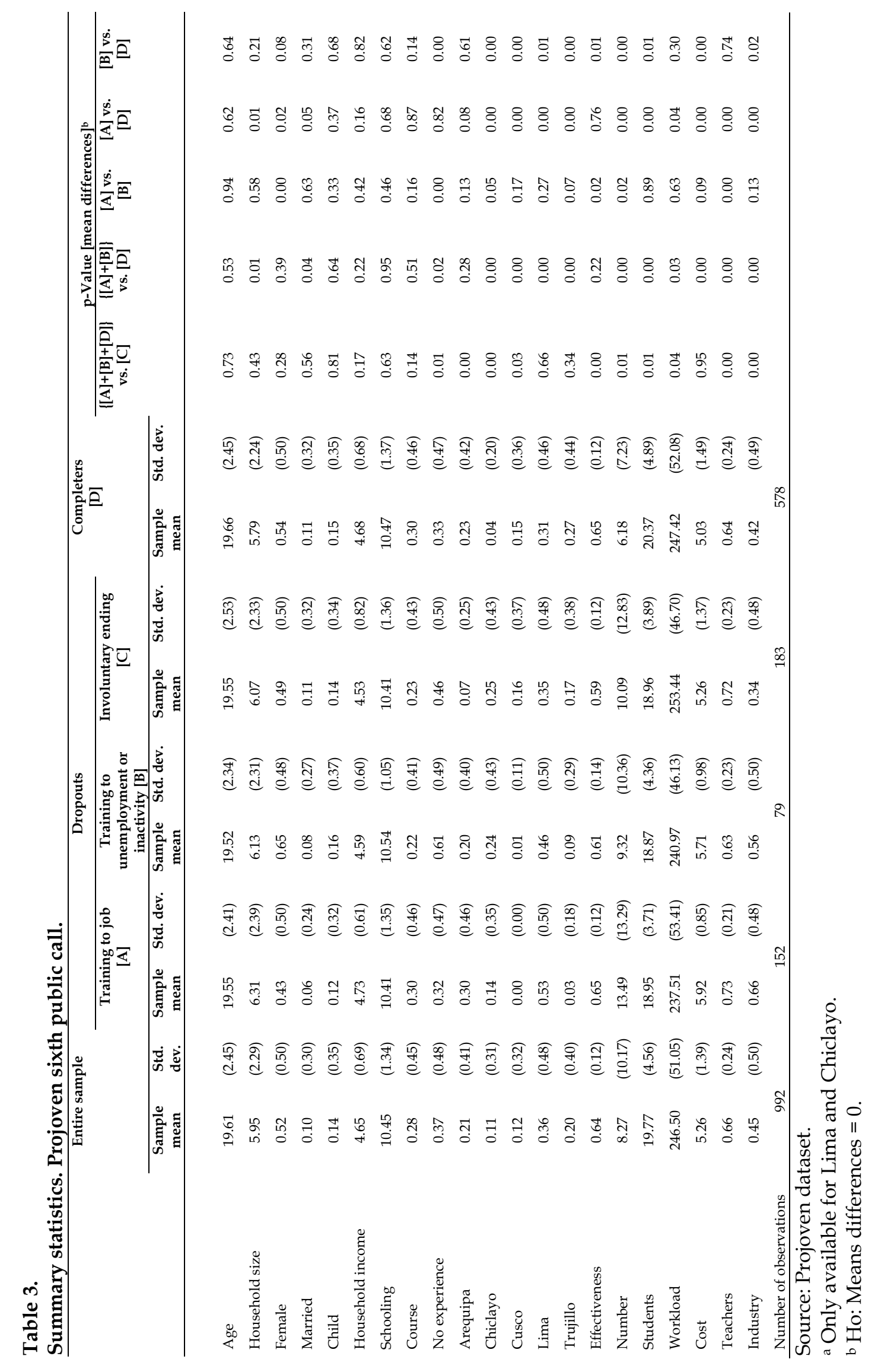




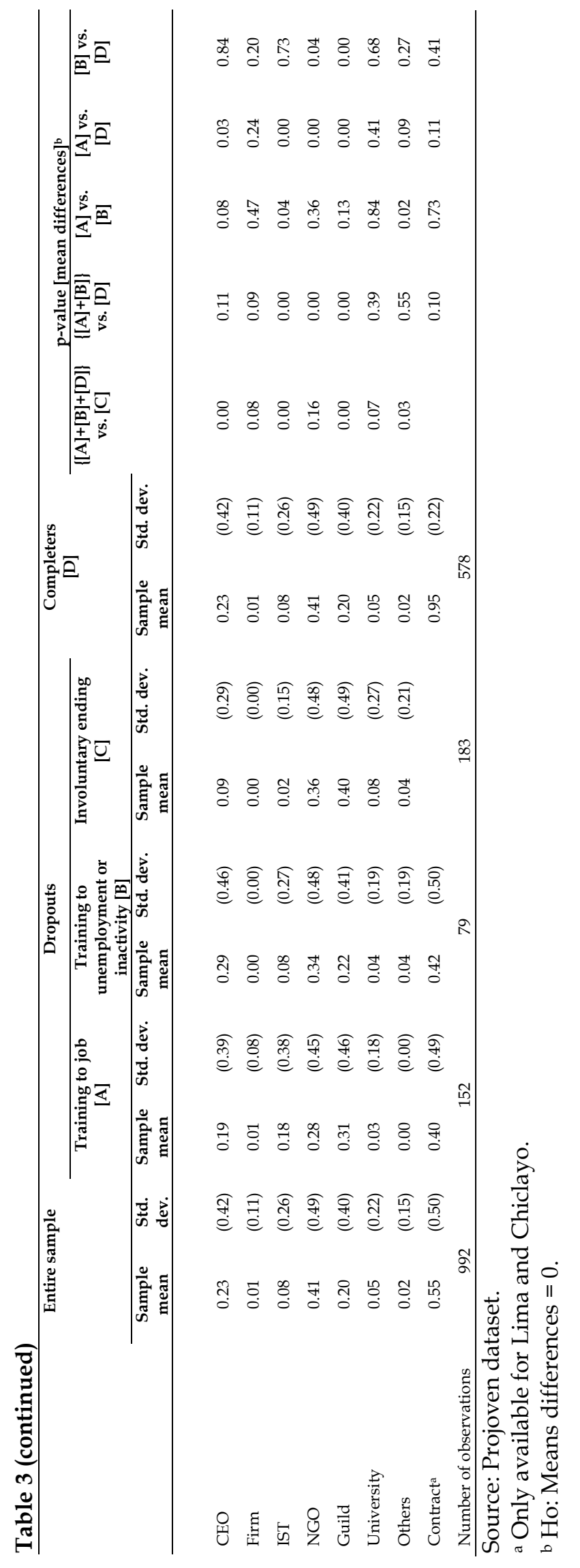


Table 4.

Trainee completion level by city. Projoven sixth public call.

\begin{tabular}{lcccccc}
\hline & Arequipa & Chiclayo & Cusco & Lima & Trujillo & Total \\
\hline $\begin{array}{l}\text { Completers } \\
\text { Dropouts }\end{array}$ & 64.4 & 22.7 & 73.5 & 49.9 & 77.9 & $\mathbf{5 8 . 3}$ \\
$\quad \begin{array}{l}\text { To a job } \\
\quad \text { To unemployment or }\end{array}$ & 22.0 & 19.1 & 0.0 & 22.4 & 2.5 & $\mathbf{1 5 . 3}$ \\
$\quad \begin{array}{l}\text { inactivity } \\
\quad \text { Involuntary }\end{array}$ & 7.8 & 17.3 & 0.9 & 10.0 & 3.5 & $\mathbf{8 . 0}$ \\
$\quad$ Total & 5.9 & 40.9 & 25.6 & 17.7 & 16.1 & $\mathbf{1 8 . 5}$ \\
\hline
\end{tabular}

Source: Projoven dataset. 
Table 5.

Probability of a Projoven internship placement. Model 1, probit estimates of the selection equation (dependent variable: internship placement $\mathbf{1}$ ).

\begin{tabular}{|c|c|c|}
\hline & Coef. & Std. err. \\
\hline Age & 0.005 & $(0.023)$ \\
\hline Household size & -0.017 & $(0.023)$ \\
\hline Female & 0.140 & $(0.117)$ \\
\hline Married & -0.386 & $(0.240)$ \\
\hline Child & 0.083 & $(0.095)$ \\
\hline Child * Female & -0.039 & $(0.092)$ \\
\hline Household income & 0.054 & $(0.065)$ \\
\hline Schooling & 0.021 & $(0.038)$ \\
\hline Course & 0.067 & $(0.118)$ \\
\hline No work experience & -0.035 & $(0.109)$ \\
\hline Arequipa & $0.654^{* * *}$ & $(0.235)$ \\
\hline Chiclayo & -0.350 & $(0.233)$ \\
\hline Cusco & -0.309 & $(0.230)$ \\
\hline Trujillo & 0.299 & $(0.220)$ \\
\hline ECAP effectiveness & 0.777 & $(0.556)$ \\
\hline Number of courses per ECAP & $-0.015^{* *}$ & $(0.006)$ \\
\hline Students per course & $0.034^{* * *}$ & $(0.013)$ \\
\hline Workload (hours) & 0.002 & $(0.001)$ \\
\hline Cost per course per trainee & $0.098^{* *}$ & $(0.048)$ \\
\hline $\begin{array}{l}\text { Teachers with }<5 \text { years of } \\
\text { experience }\end{array}$ & 0.357 & $(0.294)$ \\
\hline Industry course & $0.319^{* *}$ & $(0.139)$ \\
\hline CEO & $0.928^{* * *}$ & $(0.183)$ \\
\hline NGO & $0.448^{* * *}$ & $(0.144)$ \\
\hline Constant & $-2.445^{* *}$ & $(1.031)$ \\
\hline Number of observations & \multicolumn{2}{|c|}{992} \\
\hline Log-likelihood ratio & \multicolumn{2}{|c|}{$\chi_{(23)}^{2}=135.59$} \\
\hline Log pseudo-likelihood & \multicolumn{2}{|c|}{-406.49156} \\
\hline Pseudo-R2 & \multicolumn{2}{|c|}{0.1429} \\
\hline
\end{tabular}

Robust standard errors adjusted for 40 clusters, by ECAP.

Base category for city dummies: Lima.

Base category for type of ECAP dummies: firm, IST, CEO, guild, university, and others. 
Table 6.

Probability of dropping out of a Projoven internship. Model 1, estimates of the response equation (dependent variable dropping out of internship $=1$ ).

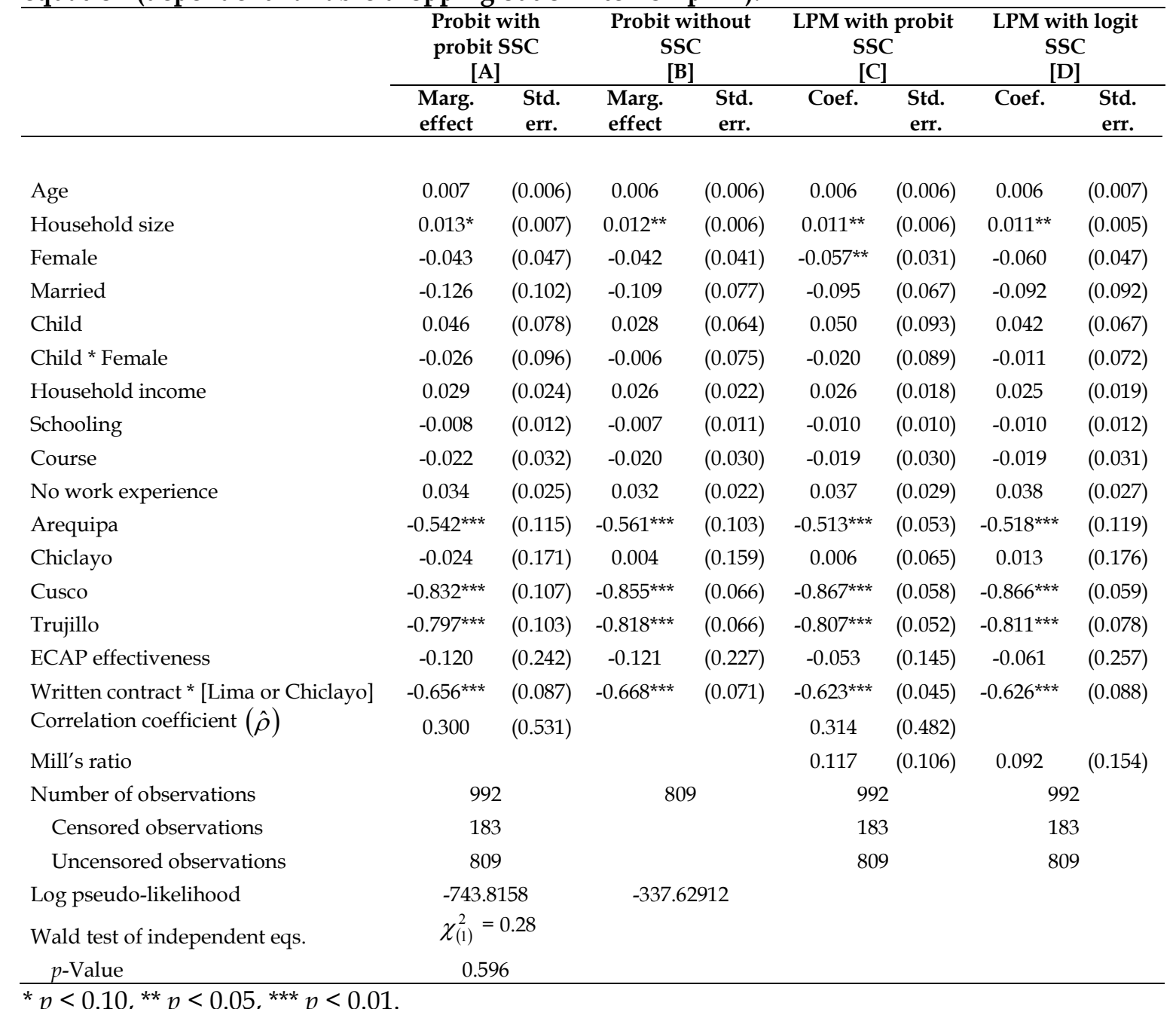

SSC stands for sample selection correction.

Robust standard errors adjusted for 40 clusters, by ECAP. Marginal effects in $[A]$ and [B] estimated at the sample median of all the variables.

Base category for city dummies: Lima. 
Table 7.

Probability of dropping out of a Projoven internship through different exit routes. Model 2, multinomial probit estimates (base category: training completion).

\begin{tabular}{|c|c|c|c|c|}
\hline & \multicolumn{2}{|c|}{ Drop out for a job } & \multicolumn{2}{|c|}{$\begin{array}{l}\text { Drop out into } \\
\text { unemployment }\end{array}$} \\
\hline & $\begin{array}{l}\text { Marg. } \\
\text { effect }\end{array}$ & $\begin{array}{l}\text { Std. } \\
\text { err. }\end{array}$ & $\begin{array}{l}\text { Marg. } \\
\text { effect }\end{array}$ & $\begin{array}{l}\text { Std. } \\
\text { err. }\end{array}$ \\
\hline Age & 0.003 & $(0.012)$ & 0.003 & $(0.011)$ \\
\hline Household size & $0.020^{*}$ & $(0.011)$ & -0.009 & $(0.011)$ \\
\hline Female & $-0.141^{* * *}$ & $(0.053)$ & $0.092^{*}$ & $(0.049)$ \\
\hline Married & -0.058 & $(0.140)$ & -0.054 & $(0.110)$ \\
\hline Child & -0.016 & $(0.191)$ & 0.051 & $(0.189)$ \\
\hline Child * Female & -0.055 & $(0.182)$ & 0.041 & $(0.180)$ \\
\hline Household income & 0.033 & $(0.040)$ & -0.004 & $(0.038)$ \\
\hline Schooling & -0.017 & $(0.019)$ & 0.009 & $(0.019)$ \\
\hline Course & 0.063 & $(0.056)$ & -0.081 & $(0.051)$ \\
\hline No work experience & $-0.162^{* * *}$ & $(0.056)$ & $0.197^{* * *}$ & $(0.055)$ \\
\hline Arequipa & $-0.385^{* * *}$ & $(0.071)$ & $-0.187^{* * *}$ & $(0.062)$ \\
\hline Chiclayo & -0.040 & $(0.094)$ & 0.045 & $(0.088)$ \\
\hline Cusco & $-0.588^{* * *}$ & $(0.072)$ & $-0.261^{* * *}$ & $(0.064)$ \\
\hline Trujillo & 0.119 & $(0.269)$ & -0.232 & $(0.251)$ \\
\hline ECAP effectiveness & $-0.572^{* * *}$ & $(0.070)$ & $-0.244^{* * *}$ & $(0.063)$ \\
\hline Written contract * [Lima or Chiclayo] & $-0.452^{* * *}$ & $(0.066)$ & $-0.216^{* * *}$ & $(0.059)$ \\
\hline Number of observations [ $\mathrm{N}=809]$ & \multicolumn{2}{|c|}{152} & \multicolumn{2}{|c|}{79} \\
\hline Overall Wald test & \multicolumn{4}{|c|}{$\chi_{(32)}^{2}=210.17$} \\
\hline Log-likelihood & \multicolumn{4}{|c|}{-466.86115} \\
\hline
\end{tabular}

${ }^{*} p<0.10,{ }^{* *} p<0.05,{ }^{* * *} p<0.01$.

Marginal effects estimated at the sample median of all the variables.

Base category for city dummies: Lima. 
Figure 1.

Distribution of trainees by participation level. Projoven sixth public call.

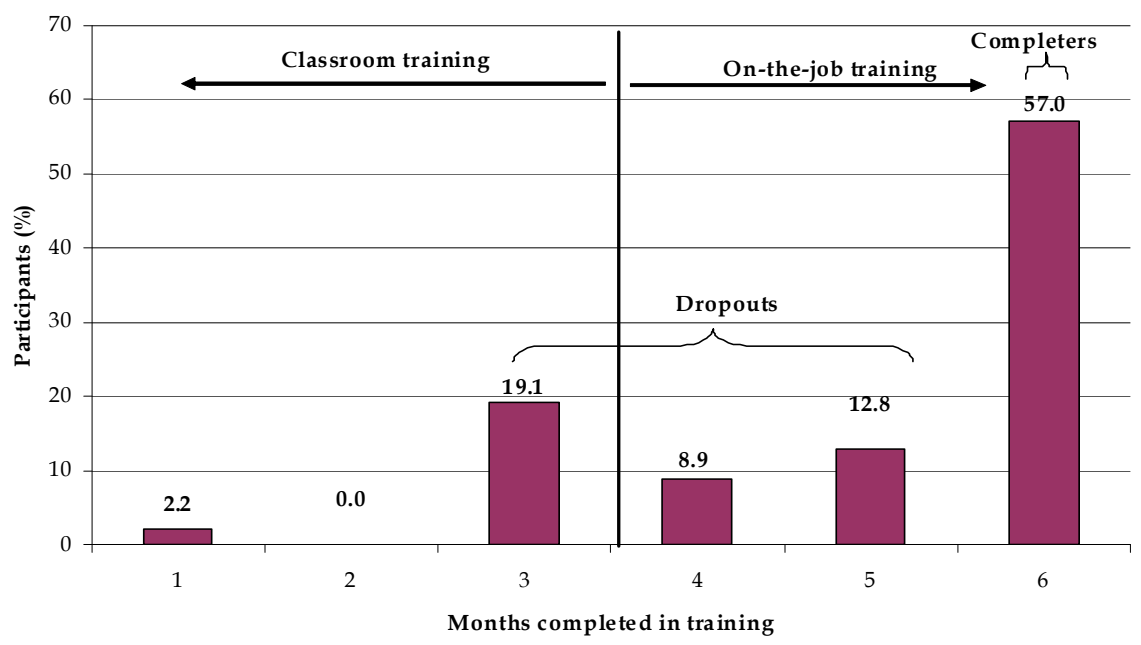

Source: Projoven. Further elaboration by the authors.

Figure 2.

Dropping out of a Projoven internship process.

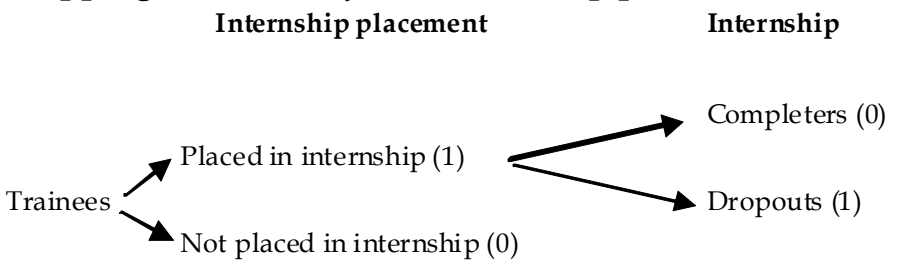

Figure 3.

Projoven internship exit routes.

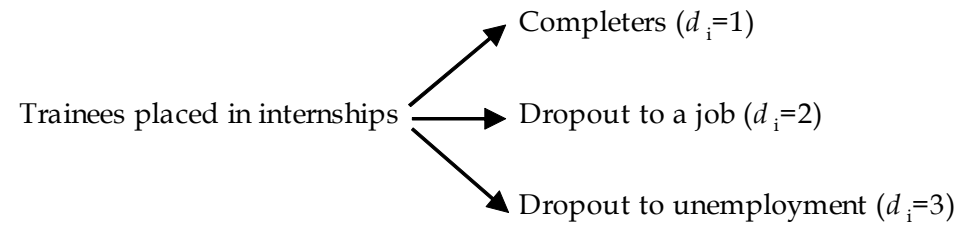

